\title{
E-AGR0: Intelligent Chat-Bot. IoT and Artificial Intelligence to Enhance Farming Industry
}

Jayalath Ekanayake, Luckshitha Saputhanthri

Sabaragamuwa University of Sri Lanka

\begin{abstract}
This study develops a chat room and a Chat-Bot to discuss the prevailing issues related to farming with peers and expertise and support farmers to make timely decision on farming. A standard set of questions was identified through discussions and surveys with farmers, expertise and other stakeholders. Intents, which the users might want to know, and examples, which the users use to explain a specific intent and entities that are different objects referring to an intent were identified from the questions. Artificial Intelligence Markup Language (AIML) was used to train a model, which predicts an intent based on the given example. The Chat-Bot was implemented in a cloud platform and therefore, the client end does not require more computational resources.
\end{abstract}

\section{Keywords}

Chat-Bot, Agriculture, Chat-room, Artificial Intelligence, Farming Industry, intents, examples.

Ekanayake, J. and Saputhanthri, L. (2020) "E-AGRO: Intelligent Chat-Bot. IoT and Artificial Intelligence to Enhance Farming Industry", AGRIS on-line Papers in Economics and Informatics, Vol. 12, No. 1, pp. 15-21. ISSN 1804-1930. DOI 10.7160/aol.2020.120102.

\section{Introduction}

The agricultural sector has been the mainstay of the Sri Lankan economy over the past centuries and currently, the sector contributes 7.5\% for the national Gross Domestic Product (GDP) of Sri Lanka and provides employments for $80 \%$ of the rural community of Sri Lanka. Agriculture by products are raw materials for the other industries, which earns foreign exchange. In Sri Lanka the agriculture industry is dominated by small-scale farmers, whose farming range is from 0.3 to 0.5 hectares. However, farming becomes less profitable industry in Sri Lanka and there is a trend that the small-scale farming community is leaving from farming.

There are many reasons for less attraction on farming. Among them lack of the knowledge on modern technologies of farming is a major problem faced by the rural community. Information is key for knowledge gain on farming and hence, information is a valuable resources for rural development (Carter, 1999; Meyer, 2003; Morrow et al., 2002) and can assist small-scale farmers in making timely decisions and taking appropriate actions. Marchionini (1995) emphasizes that people need to change the state of their knowledge to access information, which implies that information is a critical resource for socio-economic development because it empowers people to make informed choices for attaining better livelihoods. Kalusopa (2005) revealed that the development in the agriculture sector is required a well organized functional integrated information delivery system, supported by efficient national collaboration programs. However, Burton (2002) noted that most people in underdeveloped communities do not know what information they lack, nor do they know that information is available to help them solve their problems. Also, Oladele (2011) observed that lack of agricultural information is a key factor that has greatly limited agricultural advancement in developing countries. Thus, agricultural information interacts with, and influences, agricultural activities in a variety of ways. This tends to imply that agricultural information can help inform decision-making regarding land, labour, livestock, capital and management. Interestingly, agricultural information is not static but, instead, needs updates through research and development. Opara (2008) mentioned that agricultural activities can arguably be improved by relevant, reliable and useful information and knowledge. Aina (1991), and Mooko 
and Aina (2007) revealed in their research findings that agricultural information is an essential recipe for successful farming. Radhakrishna (2007) pointed out the other externalities such as money, favorable socio-political stability, and good governance that have to be in place so that information can make an impact. Invwieri (2007) opined that, rural community who are mainly illiterate require access to appropriate information to be able to make decisions and participate fully in the national development processes, including agriculture. However, the literacy rate of the rural community in Sri Lanka is higher compared to the other countries in the region and hence, providing necessary infrastructure will enable them to access the right information at right time. Zhao (2008) pointed out that the Internet adoption is required to empower the rural society since the majority of the people in developing countries belong to rural communities. Galagedarage (2015) identified the relationship between Internet adoption and infrastructural facilities, the adopter characteristics of rural communities, the characteristics of technology and affordability. Further, she explored that the issues such as lack of infrastructural facilities, problems of affordability and low computer and English language skills, negative attitudes, relevancy, and a lack of knowledge about benefits and usage of the Internet are negatively impact on Internet adoption among rural communities in Sri Lanka.

All the above research findings revealed that the development in the agriculture field needs crucial information to be made easily accessible, particularly to the small-scale farmers. Also, it reveals that productivity of farming can be improved by providing right type of information and at the right time, using the right channels and with all other necessary infrastructure in place, like telecommunication facilities, access roads, education, agricultural policies.

The state institutions of Sri Lanka and the private sector have taken several measurements to improve the IT infrastructure as well as the IT literacy in rural areas. Further, they have taken some initiatives to disseminate information through Information Technology. To that end the Department of Agriculture of Sri Lanka has developed several systems to provide information and disseminate knowledge among the rural farming community. The official website of the Department of Agriculture - www.doa.gov.lk - has been started since 2005 in English medium but later it was revamped and developed in all local languages Sinhala and Tamil. The web portal Wikigoviya
- wwww.goviya.lk - was built to facilitate progressive dialogues on agricultural issues (Agriforum) and establish public knowledge repository called Agripedia. It also facilitates distance learning in agriculture and ICTs (e-learning). The e-SMS Service, which the farmers can send messages to an expert team called krushifm to discuss their maters in radio programs or send messages to Call Centre team requesting advice on their issues. All the above methods do not provide real-time interaction between farmers and experts.

Meeting with an agent of the Agricultural Department to solve certain issues related to farming is a traditional way of knowledge sharing and it is still practicing in Sri Lanka. However, this is very inconvenient to the farmers as the agent can be met only on scheduled dates. All of the above methods are not interactive and not real-time and hence, they are not popular among the farming community.

Jayarathna and Hettige (2013) developed a multiagent system, which represents farmers, sellers, buyers and agricultural instructors and provided facilities to communicate with each other. This system used the multi-agent technology and is somewhat similar to our system, but we used the Chat-Bot technology, which received wider attention recently and used for several applications. The first Chat-Bot was the Eliza program (Weizenbaum, 1966). Later, Richard Wallace wrote A.L.I.C.E., the Artificial Linguistic Internet Computer Entity, a new Chat-Bot program (Wallace, 2003). It won the Loebner Award, which is the first formal instantiation of a Turing Test. A.L.I.C.E. was later updated by Dr. Wallace, Jon Baer, and others and programmed in Java. They later set up the Alice AI Foundation to promote the programming of Alicebots and help direct the new Artificial Intelligence Mark-up Language (AIML). The open source platforms like Dialogflow, IBM Watson can be used to build the Chat-Bot. However, the Chat-Bot technology has not been used in Agriculture domain very often.

Hence, this project aims on developing a web based interactive and intelligent Chat-Bot for farmers to discuss their issues. Further, this project implements a chat forum to interact with peers and share their knowledge and experiences. As the Internet infrastructure and mobile technology are rapidly developing in the rural areas, the rural community can access these systems at anywhere, anytime and from any device. 


\section{Materials and methods}

\section{WebSocket}

Websocket exchanges text and binary data with client and server. It opens up interactive communication sessions between user and server that user can send messages to server and get an event driven response without poll the server to reply. Unlike http it is full-duplex and real time data flow.

On the request of client the server gives access to chat application through opening a websocket between client and server. All the connected clients have separate websocket connections toward the server. When a client sends message to the server through the chat application, server sends that message to the other connected clients through the websocket. So the others can display the message in their chat. The communication channel can be secured by applying Transport Level Security (TLS).

\section{Socket.io}

Socket.io is an event based emulation of websocket. It is a javascript library that can use for real-time web application. It is build on the top of Engine.IO. It primarily uses protocol of websocket and AJAX long polling for transport. It has two parts clientside and server-side libraries. It has cross browser and is working for all browsers now.

The chat room is integrated into E-Agro platform server, which is working on node server. It uses Socket io and express js. We installed the required libraries; express, socket.io and http and set the paths for the front-end and the server. The front-end of the application is implemented by using angular js as shown in the Figure 1 and the bootstrap framework is used to develop the chat application.
The chat-room is mainly comprised of messagebox, send button and the view of the other group members. The interface is made considering the standard features such as clarity, consistency, feedback, assistance and guidance, and user centric.

Google Translation API is used to translate messages between English and Sinhala. This is a simple tool to interact with other people and share their knowledge and experiences in their own language.

\section{AI Chat-Bot}

Chat-Bot is a latest technology to duplicate human conversation. Artificial Intelligence (AI) technologies and natural language processing techniques are integrated into the Chat-Bot. The Chat-bot can be trained to convers with human in any domain.

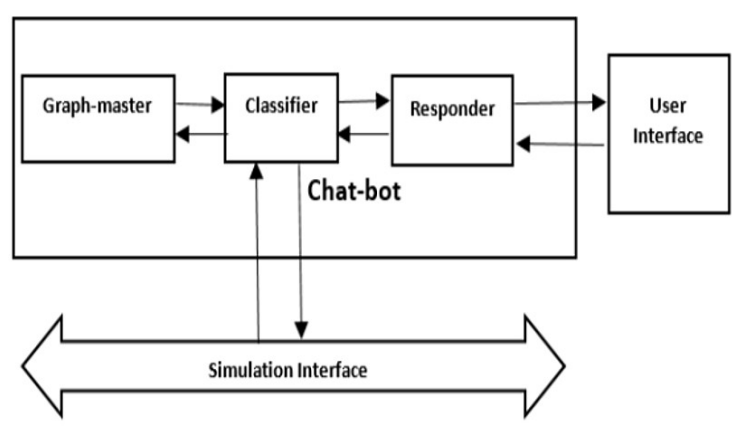

Source: Stoner, 2004

Figure 2: Chat-Bot Components.

As in the Figure 2 the Chat-Bot has three major components: Responder, Classifier, and Graphmaster. Through the user interface user send response to the responder. The responder transfers data from user to classifier and the other side. Classifier filters and normalizes inputs and passes them to the Graph-master. Graph-master is the brain

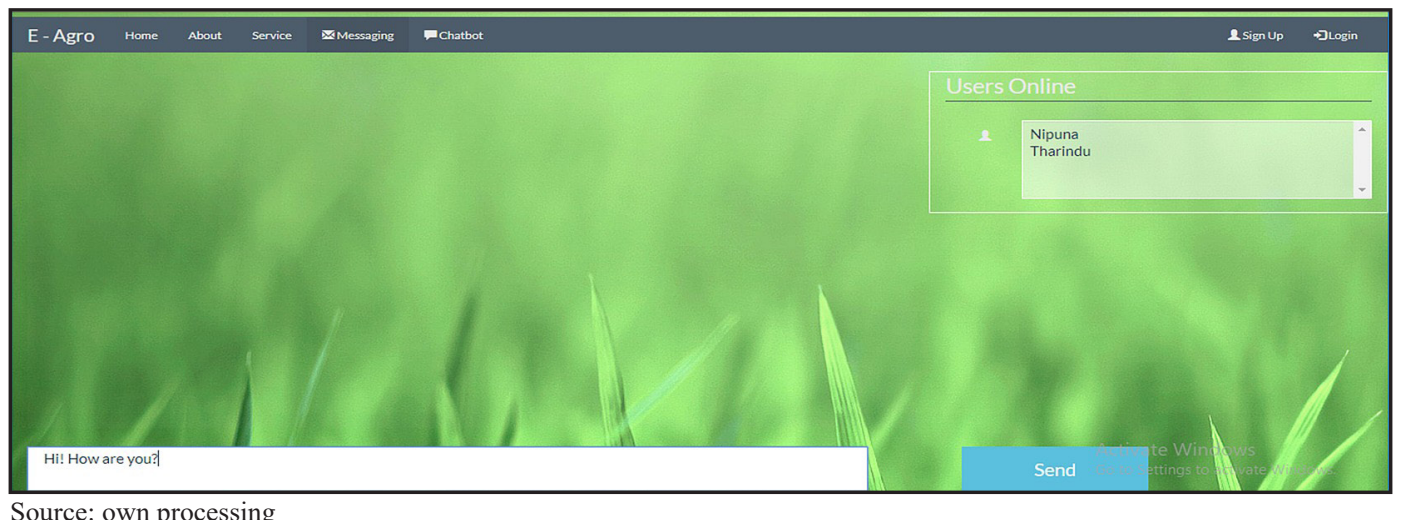

Figure 1: Chat room interface. 
of the Chat-Bot. It matches the patterns with the stored information and sends them to the classifier. Then classifier also process the output respond.

Artificial Intelligence Markup Language (AIML) is used to encored the graph master representing examples and their corresponding intents. Following is a sample code of AIML.

$<$ ?xml version="1.0" encoding="ISO-8859-1"?>

$<$ aiml $>$

$<$ category $>$

$<$ pattern $>$ HELLO $*<$ pattern $>$

$<$ template $>$ Hi. $</$ template $>$

$</$ category $>$

$</$ aiml $>$

The above example code generates the intent response "Hi" for the input example "Hello".

When generating intents the sub categories of intents are also generated. For an example if a user example describe a location with an image then the intent response is an image of the location.

Adding more examples, which describe the same intent, can increase the accuracy of the Chat-Bot.

In this project the intents and the examples were collected through questionnaires, interviews with farmers, expertise and other stakeholders in the agricultural domain. The intents and the examples are the data used to train the ChatBot. The Chat-Bot is trained to predict an intent for the given example.

The user input text that is an example, is split into words and labeled according to their positions. Next according to different disciplines of grammar the words are chunk while omitting the unwanted words. Then important words are checked against key words and corrected them if necessary. The word pattern is passed into graphmaster to retrieve the corresponding pattern from the knowledge base.

The open source platforms like Dialogflow, IBM Watson can be used to build the Chat-Bot as it allows both text and voice and also, a user can create their own intents, entities and context, and train the Chat-Bot easily.

\section{Results and discussion}

\section{Translation Chat-Room}

The Figure- 3 shows the user interface of the chat room. The conversation is in the local language Sinhala. The user interface was developed considering the properties such as guidance, user-in-control, consistency, prevent errors, feedback, and simplicity. Also, the interface should provide facilities for the illiterate farmers. The task analysis was conducted with farmers, expertise in the field of agriculture and the expertize group of academics in User Interface designing at our university to identify and trace the tasks and subtasks, which the user requires to accomplish in order to successfully interact with the interface as mentioned by (Johnson, 1992). The initial version of the interface was designed with the help of the UI design group of our university accommodating all the requirements of the users. The initial version of the interface was presented to 40 farmers selecting from different areas in Sri Lanka. Mostly, they agreed on the objects presented in the interface however, they found difficulties in identifying the objects. Also, the majority did not agree on the organization of the objects. Hence, we changed the appearance of the objects as well

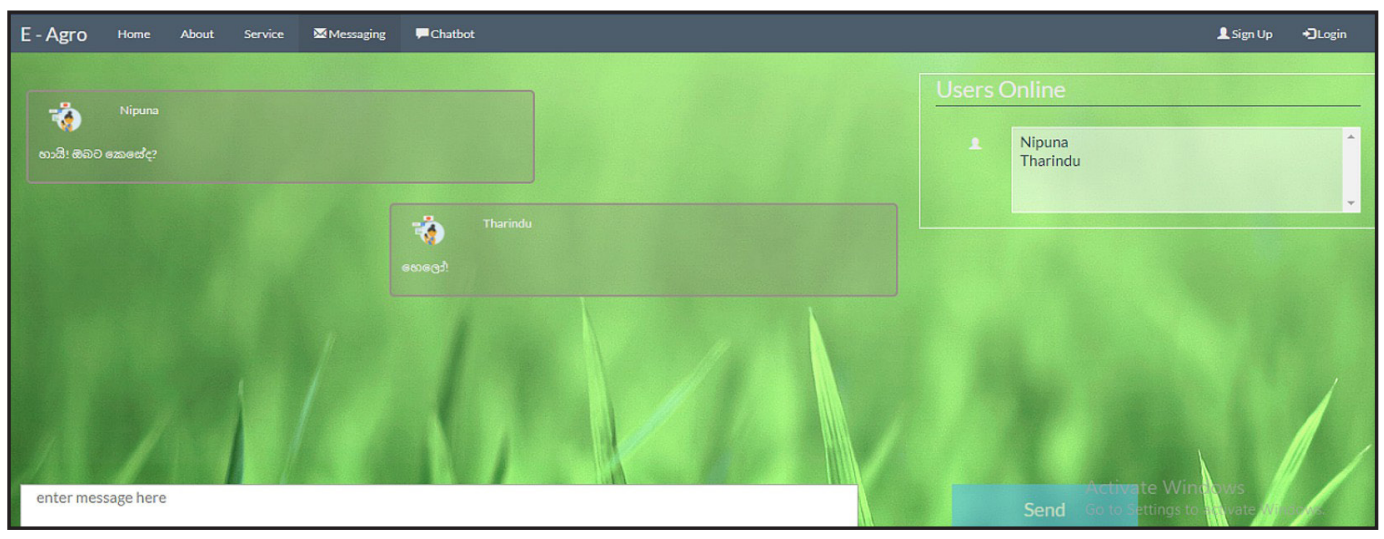

Source: own processing

Figure 3: User interface of the chat room. 
as the organization of the objects and finalized the interface as shown in Figure 3. The usability test of the interface was conducted in the laboratory with the help of the UI group at our university. The test was successful and subsequently, the usability test was conducted with real users in the field. This time we selected different set of farmers, who did not involve in the feedback session conducted at UI design stage. The majority of farmers successfully used the chat room without a difficulty and they impressed about the system. However, they found somewhat difficulty in the keyboard layout and hence, a user-friendly keyboard layout is required to design specially targeting the farmers.

\section{Chat-Bot}

Figure 4 shows the interface of the Chat-Bot. The interface was designed using the same procedure as above. The test was conducted in the laboratory and subsequently in the field. Test samples were selected from the frequently asked questions. Most of the test samples were drawn from the examples used to train the Chat-Bot. However, the test examples were slightly revised so that the Chat-Bot was tested with new queries, which are not seen by the Chat-Bot during the training. Some of the examples are included for greeting based on the time and some examples introduce the Chat-Bot itself to the users. Table 1 shows 13 test samples of user inputs and the Chat-Bot responses out of more than 50 test cases. The first three test cases are for the greeting and the introduction. The Chat-Bot is trained with examples, which are atomic sentences. The atomic sentences are not combined with logical connectors; AND and OR. The Chat-Bot failed to answer the questions 6 and 7 as they are not atomic questions. Also, the Chat-Bot did not answer for the question 8 as the required information is not stored in the knowledge base. The intents for the examples from 9 to 13 were identified in our previous research (Tharindu and Ekanayake, 2018) and the provided intents by the Chat-Bot for the given examples are correct. The system developed by Jayarathna and Hettige (2013) is somewhat similar to our system. They used multi-agent technology while we used Chat-Bot technology, which is widely used in applications like question-answering systems in many areas. Also, our system is interactive and the farmers' feedbacks indicated that it is user-friendly and a useful tool, which can assist for decisionmaking and information delivery in real-time. The web portal wwww.goviya.lk managed by the Department of Agriculture in Sri Lanka is not a truly question-answering system and hence, the farmers want to spend more time to search information. Also, the e-SMS service is not real-time system and hence, it is not popular among the farming community.

In general, the Chat-Bot provides reasonably correct answers for the given quires. Further, the farmers, who involved for the evaluation process accepted the Chat-Bot as a user-friendly and helpful tool for their farming industry. Hence, they are willing to use it in future farming activities. However, the Chat-Bot is required to train with the composite examples, which two or more

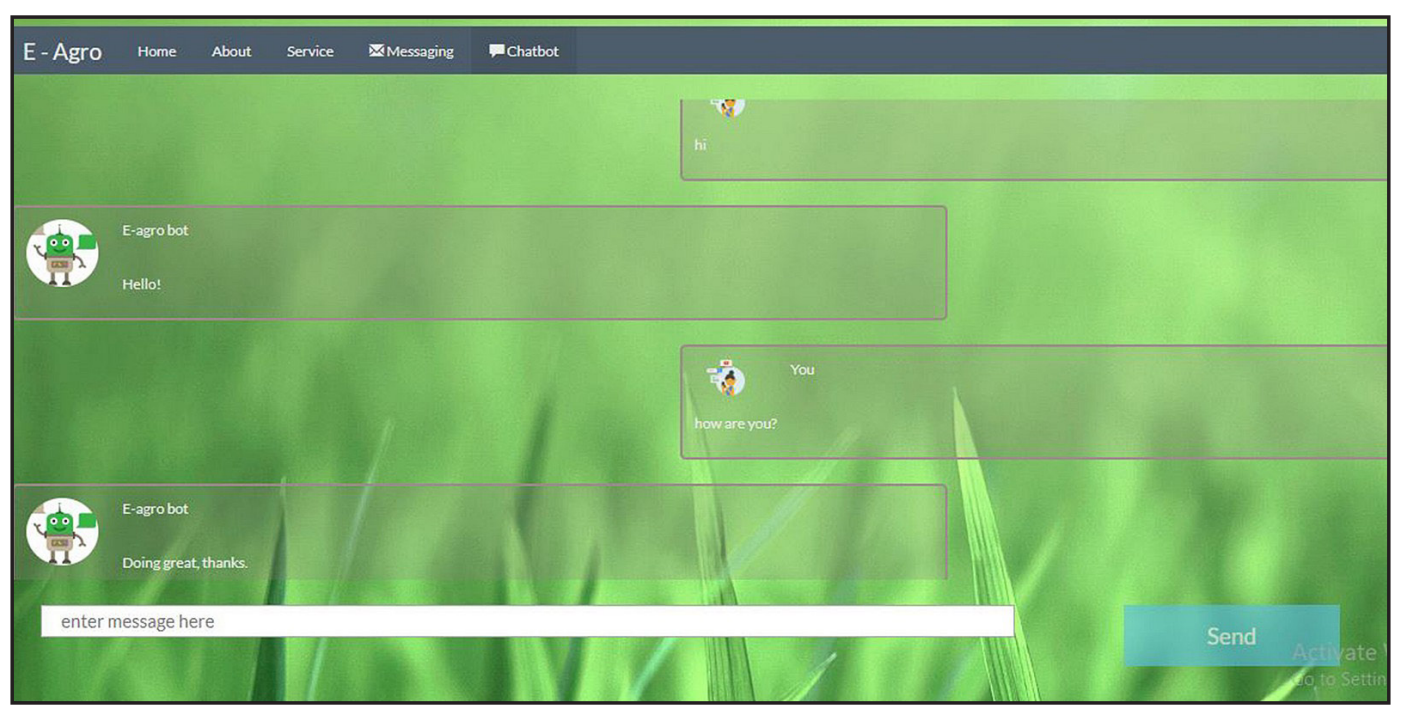

Source: own processing 
examples are connected using logical operators. Further, the Chat-Bot does not provide answers if the required information is not encoded into its knowledge base. Therefore, the knowledge base of the Chat-Bot is required to populate with more examples and intents.

\begin{tabular}{|c|c|c|}
\hline & User's Inputs & Chat-Bot Response \\
\hline 1 & $\mathrm{Hi}$ & Hello \\
\hline 2 & How are you? & Doing great, thanks \\
\hline 3 & Who are you? & $\begin{array}{l}\text { I'm a bot that can help } \\
\text { you to get knowledge } \\
\text { about farming, } \\
\text { and economic status } \\
\text { of plants }\end{array}$ \\
\hline 4 & $\begin{array}{l}\text { Crops suitable for grown } \\
\text { in Monaragala district }\end{array}$ & tomato, maize. \\
\hline 5 & Crops suitable for Badulla district & potatoes \\
\hline 6 & $\begin{array}{l}\text { Crops suitable for rainy season } \\
\text { in Monaragala and Badulla? }\end{array}$ & $?$ \\
\hline 7 & $\begin{array}{l}\text { Different soils existing in Monaragala } \\
\text { and Badulla area? }\end{array}$ & $?$ \\
\hline 8 & Cost for growing tomato & $?$ \\
\hline 9 & Best time period to grow green gram & April, May, June, July \\
\hline 10 & Best time period to grow maize & November, December \\
\hline 11 & Best time period to grow potato & $\begin{array}{l}\text { June, July, August, } \\
\text { November, December }\end{array}$ \\
\hline 12 & Best time period to grow red onion & January \\
\hline 13 & Best time period to grow tomato & $\begin{array}{l}\text { June, July, November, } \\
\text { December }\end{array}$ \\
\hline
\end{tabular}

Source: own processing

Table 1: Sample test cases.

\section{Conclusion}

Agriculture is the main industry in the rural areas of Sri Lanka and the agriculture contributes a significant amount to the economy of Sri Lanka. However, the agriculture is becoming less profitable

Corresponding authors

Jayalath Ekanayake

Sabaragamuwa University of Sri Lanka, Belihuloya 70140, Sri Lanka

Phone: +94711954433, E-mail: jayalathek@appsc.sab.ac.lk

\section{References}

[1] Aina, L. O. (1991) "Information for successful agriculture", Journal of Library and Information Science, Vol. 2, No. 1, pp. 1-6. E-ISSN 2374-2364, ISSN 2374-2372.

[2] Burton, S. (2002) "Development at any Cost: ICTs and People's Participation in South Africa Communication", Communicatio, Vol. 28, No. 2, pp. 43-53. ISSN 0250-0167. DOI 10.1080/02500160208537941.

[3] Carter, I. (1999) "Locally Generated Printed Materials in Agriculture: Experience from Uganda and Ghana", Education Research Papers 12845, Department for International Development (DFID) (UK). industry and hence, there is an inclined trend that the rural community keeps away from agriculture. There are many reasons for this development. Among them accessing information at right time about agriculture is a major issue.

Hence, the aims of this project are to network To that end, we developed a chat room Further, we developed an intelligent Chat-Bot, which provides solutions for certain issues of farmers through an online system.

The intents and examples were extracted through questionnaires and interviews with farmers and expertise. The knowledge base of the ChatBot is programed using the Artificial Intelligent Markup Language (AIML). The Chat-Bot is trained using the atomic examples to predict the intents. Interface.

The chat room and the Chat-Bot were evaluated in the laboratory and with farmers. The farmers accepted the tools and they are willing to use them their farming activities. examples. Further, the Chat-Bot is trained in a small domain and hence, it's capabilities are limited. As a pilot project the data is collected only on two districts in Sri Lanka, but in future, it will be covered the whole country. The Chat-Bot is designed and implemented in cloud platform and hence, the client end is not required more computing power. farmers and provide solutions to farmers' issues 
[4] Galagedarage, G. T. M. (2015) "Issues in Internet Adoption and Rural Empowerment in Sri Lanka", Journal of Humanities \& Social Sciences, Vol. 09. ISSN 1934-7227.

[5] Invwieri, J. W. (2007) "Information needs of illiterate female farmers in Ethiope East local Government Area of Delta State, Nigeria”, Library Hi Tech News, Vol. 24, No. 9/10, pp. 38-42. ISSN 0741-9058. DOI 10.1108/07419050710874278.

[6] Jayarathna, H. and Hettige, B. (2013) "AgriCom: A communication platform for agriculture sector", Conference paper: Agricultural Communications Documentation Center (ACDC), USA: IEEE, New York City, New York, pp. 439-444. DOI 10.1109/ICIInfS.2013.6732024.

[7] Johnson, P. (1992) "Human Computer Interaction: Psychology, Task Analysis, and Software Engineering”, Berkshire: McGraw-Hill Europe. ISBN 10: 0077072359, ISBN 13: 978-0077072353.

[8] Kalusopa, T. (2005) "The Challenges of Utilizing Information Communication Technologies (ICTs) for the Small-Scale Farmers in Zambia”, Library High Technology, Vol. 23, No. 3, pp. 414-424. ISSN 0737-8831. DOI 10.1108/07378830510621810.

[9] Marchionini, G. (1995) "Information Seeking in Electronic Environments", Cambridge: Cambridge University Press. E-ISBN 9780511626388. DOI 10.1017/CBO9780511626388.

[10] Meyer, H. W. J. (2003) "Information Use in Rural Development", The New Review of Information Behaviour Research, Vol. 4, No. 1, pp. 109-125. E-ISSN 1740-7877, ISSN 1471-6313. DOI 10.1080/14716310310001631471.

[11] Mooko, N. and Aina, L. O. (2007) "Information Environment of Artisans in Botswana", Libri Journal, Vol. 57, pp. 1-7. ISSN 0024-2667. DOI 10.1515/LIBR.2007.27.

[12] Morrow, K., Nielsen, F. and Wettasinha, C. (2002) "Changing Information Flows", LEISA Revista de agroecología, Vol. 18, No. 2, pp. 4-5. ISSN 1729-7419.

[13] Oladele, O. I. (2011) "Effect of Information Communication Technology on agricultural information access among researchers, extension agents and farmers in South Western Nigeria", Journal of Agriculture and Food Information, Vol. 12, pp. 167-176. E-ISSN 1540-4722, ISSN 1049-6505. DOI 10.1080/10496505.2011.563229.

[14] Opara, U. N. (2008) "Agricultural information sources used by farmers in Imo is isẹpiState, Nigeria", Information Development, Vol. 24, No. 4, pp. 289-292. E-ISSN 1741-6469, ISSN 0266-6669. DOI 10.1177/0266666908098073.

[15] Radhakrishna, R. B. (2007) “Approaches for linking markets and farmers to foster indian'srural development”, Proceedings of the $24^{\text {th }}$ Annual Meeting, E.A.R.T.H. Costa Rica, 1-17.

[16] Stoner, D. J., Ford, L., and Ricci, M. (2004) "Simulating Military Radio Communications Using Speech Recognition and Chat-Bot Technology”, The Titan Corporation, Orlando.

[17] Tharindu, S. and Ekanayake, J. (2018) "Data Mining Approach to predict Suitable Seasons to Cultivate Crops", EdHat IRCICT: International Research Conference on ICT, Colombo Sri Lanka.

[18] Wallace, R. (2003) “The elements of AIML style," Alice AI Foundation. 139

[19] Weizenbaum, J. (1966) "ELIZA - a computer program for the study of natural language communication between man and machine", Communications of the ACM, Vol. 9, No. 1, pp. 36-45. E-ISSN 1557-7317, ISSN 0001-0782. DOI 10.1145/365153.365168.

[20] Zhao, J (2008) "ICT4D: Internet Adoption and Usage among Rural Users in China", Knowledge, Technology \& Policy”, Vol. 21, No. 1, pp. 9-18, E-ISSN 1874-6314, ISSN 0897-1986. DOI 10.1007/s12130-008-9041-0. 